\title{
Authors' reply to: Letter to editor regarding "The endoscopic diving technique in endonasal transsphenoidal surgery: how I do it"
}

\author{
Davide Locatelli $^{1} \cdot$ Sergio Balbi ${ }^{1} \cdot$ Pierlorenzo Veiceschi $^{1,2}$ (D) \\ Received: 25 May 2020 / Accepted: 27 May 2020 / Published online: 5 June 2020 \\ (C) Springer-Verlag GmbH Austria, part of Springer Nature 2020
}

To the Editor:

We carefully reviewed the letter from Ceraudo et al. in reply to our technical note [5], and we sincerely thank the Editor for giving us the opportunity to debate about this topic.

We appreciated their favorable opinion regarding the endoscopic diving technique (EDT), which we introduced in our surgical practice for a long time. It allows, among many other things, to hydro-dissect tumor remnants and to improve the visualization of the surgical field in an "underwater" fashion, as described elsewhere $[3,4]$.

Ceraudo and colleagues had previously provided their preliminary experience with this technique by adopting a different system from ours, that separates the irrigation source from the optic [1]. This modification may require more space and less freedom of movement inside the surgical cavity, but it is useful in the perspective of looking for innovations. Since then, their proficiency seems to be further improved through the integration of Ultra High Definition and 4K systems, along with other irrigation devices from various medical companies.

In the last few years, several papers have been published on the use of EDT in skull base surgery: this testifies a growing consideration $[1,2]$. It will certainly be interesting to know new up-to-date case histories even from other different groups and to analyze their learning curve after the application of this

This article is part of the Topical Collection on Pituitaries

Pierlorenzo Veiceschi pierloveiceschi@gmail.com

1 Division of Neurosurgery, Department of Biotechnology and Life Sciences, Ospedale di Circolo e Fondazione Macchi, University of Insubria, Viale Luigi Borri, 57, 21100 Varese, Italy

2 Department of Neurosurgery, Fondazione IRCCS Policlinico S. Matteo, University of Pavia, Pavia, Italy technique in everyday surgical activity. We rely that a significant step forward will be performed as soon as specific tools will be available, so that they could allow working underwater, similarly to intraventricular neuroendoscopy.

\section{Compliance with ethical standards}

Conflict of interest The authors declare that they have no conflict of interest.

Ethical approval All procedures performed in studies involving human participants were in accordance with the ethical standards of the institutional and/or national research committee and with the 1964 Helsinki declaration and its later amendments or comparable ethical standards.

Abbreviations $E D T$, endoscopic diving technique

\section{References}

1. Ceraudo M, Anania P, Prior A, Criminelli D, Zona G (2019) Modified endoscopic diving technique without the traditional irrigation system in endoscopic cranial base surgery: technical note. World Neurosurg 127:146-149

2. Gao HB, Wang LQ, Zhou JY, Sun W (2018) Investigating the application of diving endoscopic technique in determining the extent of pituitary adenoma resection via the trans-nasal-sphenoidal approach. Exp Ther Med 15(4):3815-3819

3. Locatelli D, Canevari FR, Acchiardi I, Castelnuovo P (2010) The endoscopic diving technique in pituitary and cranial base surgery. Neurosurgery 66(2):E400-E401

4. Locatelli D, Veiceschi P, Castelnuovo P (2019) Letter to the editor regarding "Modified endoscopic diving technique without the traditional irrigation system in endoscopic cranial base surgery: technical note". World Neurosurg 128:634-635

5. Locatelli D, Balbi S, Veiceschi P (2020) The endoscopic diving technique in endonasal transsphenoidal surgery: how I do it. Acta Neurochir. https://doi.org/10.1007/s00701-020-04369-8

Publisher's note Springer Nature remains neutral with regard to jurisdictional claims in published maps and institutional affiliations. 